\title{
Sobre la universidad ${ }^{\mathrm{A}}$
}

\section{Germán Colmenares}

El cierre de la Universidad Nacional produjo un resultado curioso. Un silencio que, este sí, parece definitivo entre los profesores universitarios. Cualquier alusión a la Universidad proviene del Gobierno o se hace en una página editorial como un eco del Gobierno. El estamento sobre el cual pesan las responsabilidades más decisivas dentro de la Universidad ha permanecido silencioso a lo largo de todas estas crisis. Solo una que otra voz, tan aislada que nunca ha llegado a sugerir siquiera la idea de un debate, se ha hecho oír y esto solo cuando algún privilegio personal le daba acceso a algún medio de comunicación. ¿Desconcierto? ¿Temor? ¿Escepticismo? Es difícil atribuir una causa precisa a este silencio.

El fenómeno hace pensar en la precariedad de la llamada libertad académica en Colombia. Para generaciones enteras de universitarios, educados en el idealismo alemán, esta libertad era el fundamento de su quehacer y podía ser defendida hasta en los últimos reductos de la conciencia mediante la afirmación obstinada de una convicción sobre un valor en sí del saber. Hoy, la familiaridad con el espectáculo real de las fuerzas sociales y con las evidencias del poder ha destruido este refugio ideológico. A lo sumo, se guarda un silencio desesperanzado en el que está ausente toda ironía. ¿Cómo ironizar ante lo que no es una mera opinión, más o menos estúpida, sino la definición misma de la realidad impuesta desde el poder?

Que toda iniciativa respecto de la Universidad provenga del Estado o de su poder entronizado en academias, en una Iglesia oficial o en un Ejército dedicado a labores de inteligencia, debería inquietar a quienes suelen pensar que viven en una sociedad libre, aun si esta libertad tiene siempre las cortapisas de su bolsa. Pero esta realidad debería ser todavía más amenazadora para quienes se dedican profesionalmente a enseñar.

En el curso de los últimos quince años las cosas han cambiado en el interior de la universidad. El populismo más o menos explícito de las ideologías tradicionales

A En El Espectador, 3 de octubre 3 de 1977. El texto, como los demás que escribió Germán Colmenares sobre la universidad en esos años, supone un conocimiento de algún detalle sobre la situación universitaria de esos años, por lo menos en la universidad pública - una situación no mejor ni peor, pero si muy diferente de la actual- . De todas maneras, el texto de Colmenares esclarece el contexto al que se refiere. Hay que recordar que la universidad fue una preocupación muy grande de los más visibles representantes de la Nueva Historia en Colombia — por ejemplo Marco Palacios, Jorge Orlando Melo y el propio Colmenares-, aunque muchas de sus proposiciones no alcanzaron la audiencia suficiente en medio de la gritería general. Se puede subrayar también que esas proposiciones, como se concretan aquí en la parte final de este texto, mantienen su validez, en tanto ellas concretan algunos fines de la institución universitaria desde el siglo XIII, a pesar de que, ayer y hoy, grupos juveniles que ante todo valorizan la acción de enfrentamiento y combate, nieguen la vocación de diálogo y confrontación civilizada que debe caracterizar la vida universitaria y la discusión de ideas. 
ha sido incapaz de adormecer por más tiempo el instinto elemental de una generación estudiantil que se sabe atada a la fatalidad histórica de su papel como pequeña burguesía. El saber, como oportunidad de prestigio y ascenso social o como orientador de un cambio nutrido de buenas intenciones, no pasa ya de ser un lugar común en los safaris electorales. Existe una oscuridad que se busca oscuramente en lo inmediato y en lo irracional y que repele por instinto cualquier abstracción ideológica. Cuando esta aparece de una manera agresiva no es otra cosa que la expresión un poco torpe de íntimos deseos individuales o de la frustración que cobija a una clase social entera. El estudiante tipo de una universidad del Estado repudia verbalmente a su propia clase, la sumisión y el conformismo que le son propios. Este repudio instintivo no puede tener una expresión propia que vaya más allá de la desconfianza mutua que se organiza en capillas minúsculas que se lanzan unas a otras la palabra infamante: "desviacionismo pequeñoburgués". El refugio natural del individualismo de la pequeña burguesía es la secta o la capilla en donde las expresiones más inmediatas del deseo o de la frustración no se pierden en la necesidad de una disciplina o en un enunciado general que busque definir la realidad.

Este desconcierto sobre los fines ha contagiado, al parecer, a los docentes de la universidad del Estado. Ninguna definición del saber resulta adecuada a las exigencias erráticas de la pequeña burguesía estudiantil y por lo tanto ningún saber puede ser presentado o construido en los claustros. Solo puede imperar la eterna sospecha sobre las trampas ideológicas del saber o algún discurso incoherente que se imponga por su incoherencia misma. El saber solo puede ser mantenido como una ilusión de algo complejo y profundo cuando cualquier enunciado sobre la realidad se sabe importante para cambiarla.

Antes que cualquier pregunta complicada sobre las trampas de la ideología, la Universidad colombiana deberá plantear, como una guía de acción, una pregunta sencilla. Primero, ¿de quién es la responsabilidad de la Universidad? Y luego ¿Cómo es posible que la Universidad exista? Habría que descartar, de entrada, la idea de que la responsabilidad de la Universidad es del Estado o del Gobierno de turno. Que la Universidad puede ser recreada a punta de decretos legislativos, de alambradas o de un eficiente control policivo. Que el nivel de eficiencia administrativa va a aumentar centralizando el control de todo gasto o recortando aún más los honorarios de profesores que tienen que recurrir a tres o cuatro "tiempos completos" para sobrevivir. La Universidad como prueba de la incompetencia de un Gobierno es un ejemplo demasiado fácil. Insistir en la idea de que el Estado o los Gobiernos serán impotentes para hacer funcionar a derechas un centro educativo a menos que su rector sea un policía es un ofrecimiento que, a la larga, ningún poder puede rehusar. Aun cuando sea para ver qué pasa.

Aunque muchas alternativas para la Universidad ya son conocidas, quedan algunas por experimentar. Una de ellas consiste en aceptar que la Universidad es la 
responsabilidad de sus estamentos. Otra, que los fines de la Universidad no están definidos por el poder que se puede alcanzar en ella sino por actividades asociadas al conocimiento. Que las actividades académicas no son un pretexto para los apetitos del poder de una capilla, secta o burocracia, sino que son la razón misma de ser de la institución universitaria. Que hay un marco de exigencias profesionales en la enseñanza que no pueden ser sustituidas por esquemas mágicos de eficacia administrativa. Que existe una dignidad inherente a la profesión docente que no puede ser reemplazada tampoco por confesiones de fe o por recomendaciones políticas. Que la Universidad no es solo un aparato ideológico del Estado, sino la única posibilidad que tiene la pequeña burguesía de alcanzar alguna lucidez sobre el mundo que la rodea.

Infortunadamente la mala conciencia no puede desterrarse en la universidad con una vaga idea de que se asiste a ella como vanguardia del proletariado o que en ella transcurre un capítulo crucial de la lucha de clases. La Universidad, debe admitirse, tiene algunas limitaciones. Pero la única que no debería tener es su disposición para crear saber. Para hacer del ocio ${ }^{\mathrm{B}}$ (esa fina flor surgida en la cúspide de todas las contradicciones sociales) una forma de acción, y del discurso una forma de conciencia articulada.

B La idea de "ocio académico", como una forma de referirse a lo que parece ser su contrario, es decir el tiempo de la investigación, este diferente del tiempo de la repetición, que irremediablemente entraña la actividad docente, fue una formulación constante en Colmenares; una idea que le gustaba precisamente porque chocaba con las ideas primerias y poco elaboradoras de la "nueva economía de la educación", señalada de manera repetida por él como la "ideología dominante" de la administración universitaria. 